\title{
The Growth of Knowledge as Grounds Against Paternalism
}

\section{Greg Clydesdale1}

This paper considers the significance of the growth of knowledge for the efficacy of paternalistic intervention. Three cases are examined. The first is government intervention in the consumption of fatty food. Second is the evolution of knowledge that occurred after a law mandated the use of cycle helmets. The third examines information flows that characterised the smoking debate. This paper argues that although knowledge continues to evolve, inertia, path dependency and expert bias can impede the removal of paternalistic laws that do not raise welfare but continue to restrict individual agency.

\section{Introduction}

Our regulatory system must protect public health, welfare and safety and our environment while promoting economic growth, innovation, competitiveness and job creation. It must be based on the best available science (Office of the Press Secretary 2011).

Paternalistic laws refer to those laws that interfere with or reduce the freedom of an individual for his or her own good; typically to 'protect or promote his health and safety, economic interest, or moral wellbeing' (Husak 2013: 40). They can help people avoid irreversible decisions that set off a cascade of problems later in life. These include growing debt, impulsive spending that doesn't improve welfare and the lack of saving.

Paternalism has been criticised for its association with coercion, removal of choice and the imposition of another party's values upon an individual, but recent research has strengthened the call for paternalist intervention. Studies in behavioural economics have revealed that consumers have cognitive limitations that limit their

1 Lincoln University, greg.clydesdale@lincoln.ac.nz. 
ability to maximise their own welfare. This has led to the rise of 'light paternalism', which argues that government intervention can compensate for these cognitive limitations and enhance welfare.

The new light paternalism has attracted new criticisms while some of the old ones remain. With this in mind, Sunstein (2011) stressed the need for empirically informed regulation. However, the introduction of a law, or any other intervention, is strongly influenced by the existing information and knowledge. It could be argued that any individual law reflects the state of knowledge that exists at the time of its introduction; however, knowledge continues to evolve long after laws have been enacted. This places an emphasis on the quality of information and measurement methodology that policy makers draw upon. It means that law and policy makers need to be fully aware of the information limitations.

This paper considers the significance of the growth of knowledge for the efficacy of paternalistic intervention. It argues that the limitations of knowledge include the nature of knowledge creation, presentation and the nature by which knowledge evolves. Our best attempts at knowledge are transient, yet it is on this basis that paternalist laws are enacted. This can reduce the logic of interventions that were introduced on the basis of the earlier knowledge. However, inertia, path dependency and expert bias can make it hard to repeal laws. These concerns apply to all regulation, but are of particular importance to paternalist laws in which the government assumes it knows what is best for the individual and can occur at a cost of individual agency. As a consequence, a society can be governed by laws that do not raise welfare. Policy makers need to recognise the nature of knowledge evolution and the limits of empirical research when making laws and policies. A number of implications are revealed for policy and law formation.

\section{Paternalism defined}

Gerald Dworkin defined paternalism as 'interference with a person's liberty of action justified by reasons referring exclusively to the welfare, good, happiness, interests or values of the person' (Dworkin 1972: 65). Its goal is typically to 'protect or promote his health and safety, economic interest, or moral wellbeing' (Husak 2013: 40).

Paternalistic policies have been criticised for a number of reasons. The assumption of superiority and the notion that the target is less capable can be considered an insult to the target (Coons and Weber 2013). As De Marneffe (2013: 72) notes, 'there is something disrespectful ... to coerce another adult on the assumption that he is mistaken about what's best for him'. Seen in this light, paternalistic laws do not respect the individual. Paternalistic laws also deny an individual's freedom and autonomy. In prohibiting or shaping an agent's decision making, it can be regarded as an affront to an agent's autonomy and freedom of choice (Muramatsu and Fonseca 
2009). If we recognise that autonomy and freedom have value in themselves, the question then becomes: to what extent can governments take them away without harming welfare? Even if the paternalistic action actually raises welfare, if an individual is forced to conform that force is a harm that may outweigh any benefit (Scoccia 2013).

However, paternalistic acts do not necessarily replace the values of the target with those of the paternalist (Coons and Weber 2013). They can, at times, help the target act consistently with their values. Often people fail to do what best reflects their values. They sometimes make mistakes and poorly considered decisions. In such cases, paternalistic interference can actually help people to achieve their rationally chosen ends (Cholbi 2013).

If a law is introduced for an individual's benefit, it raises the question of how that law should be enforced. The purpose of a paternalistic law is to benefit a person, but if they are punished or disadvantaged for not wanting to reap those benefits, we are in fact imposing harm and reducing their welfare (Husak 2013).

This raises the question of whether governments should be able to restrict someone's actions and impose a benefit on them, even if they do not want that benefit. Wellman (2005) argues that it is not necessarily wrong to place a benefit upon someone without that person's consent, but it cannot be justified in terms of benefiting that person. The paternalist claims to benefit that person, and may do so, but frequently the greatest benefit goes to those making the imposition. The paternalists succeed in imposing their standards on another person who have their liberty restricted, their choice taken away and judgement overridden.

This situation is made possible by the nature of the political process. Leoni (1991: 8) notes that legislation 'always reflects the will of a contingent majority within a committee of legislators who are not necessarily more learned or enlightened than the dissenters'. Not only does the will of the majority facilitate the legal process, it also adds an air of intellectual legitimacy, in that most people will agree with the action. However, the phrase 'most people don't mind' paves the way for a minority to lose their freedom. The consequence can be a gradual loss of aggregate freedoms as minority freedoms are overridden one by one.

\section{New paternalism}

The new paternalism seeks to overcome many of the criticisms of paternalism. The 'new' or 'liberal' paternalism refers to interventions that affect consumer behaviour but maintain an individual's freedom to choose. New paternalism was advanced by Thaler and Sunstein (2009) with the purpose of compensating for the cognitive and informational limitations of decision makers. People are nudged, not forced, into making decisions that are more likely to enhance their welfare. 
The new paternalism uses a number of tools to nudge people towards welfareenhancing decisions. These include informational interventions to increase the quality of their decision making, and default rules in which people must choose to opt out of a good decision (not the other way around). Another is the use of temporary cool-down periods, which allow time for a more considered decision, and, finally, changes can be made in the decision-making environment that are more likely to lead to a better-quality decision. This 'choice architecture' is useful to counter the distortions that already exist in the environment, such as those placed by advertisers in store designs aimed at increasing sales.

The new paternalism claims to avoid many of the problems of traditional paternalism as individuals still retain the element of choice and make decisions based on their own goals and values. Individuals are not punished under the new paternalism, although there may be limits to that claim. Loewenstein and O'Donoghue (2006) note that if such things as over-indebtedness, under-saving or obesity are promoted as undesirable, this can lead to feelings of shame and guilt, which in turn may reduce the individual's autonomy and free will.

Despite its advantages, the new paternalism has been the target of a number of criticisms. First, if the decision-making weaknesses are characteristic of humans, the paternalists would also be prone to these errors, including emotional biases in judgement (Blumenthal 2007). Second, in directing people to the best choices, it denies people the chance to learn and develop their own decision-making capabilities. Third, in making it harder for people to make certain choices, people preferring options not favoured by the paternalists will endure increased difficulties and costs (see Rizzo and Whitman 2009a).

Fourth, such interventions could have negative impacts on unintended targets. For example, policies highlighting the dangers of over-eating could have a negative impact on young girls who become too weight conscious (Gill and Gill 2012). Policy programs regularly promote awareness of worst-case scenarios akin to scaremongering. Finally, Glaeser (2005) notes that consumers have stronger incentives to get things right than government decision makers, who have their own self-interest and have to contend with lobby groups and vote trading.

On philosophical grounds, new paternalism has been criticised for emphasising welfare over other values such as freedom and autonomy. 'Nudges' may not be as intrusive as coercion, but they are manipulation nevertheless and reduce the amount of control that people have over decision making. This manipulation has been justified because much of the choice environment has been structured by people such as advertisers who have no concern for our well-being (Blumenthal-Barby 2013). In such cases, the paternalist action is merely restoring balance. However, this can lead to another criticism in that it creates multiple layers of manipulation, with corporate manipulation overlaid with government manipulation. 
Although new paternalism is claimed to be moderate, Rizzo and Whitman (2009a) argue that it opens the possibility of more extreme measures. This occurs because it is easy to extend a policy once it has been introduced. This slippage is augmented by the lack of demarcation lines, the vagueness of many of the terms and analyses, the pressure of lobby groups, and the policy makers' own cognitive biases. But most concerning is the new paternalistic framework in itself, which makes intervention acceptable. Their argument is convincing but has one important weakness. Their 'thin end of the wedge' argument means that good interventions may be overlooked on the basis of what they may lead to, not on their own merits.

One of the benefits of government decision making is that it can draw on acknowledged experts, who have deeper knowledge on their chosen subject, have access to more information and know how to interpret that information. Not surprisingly, research shows that experts, including teachers, pilots, weather forecasters, lawyers, trial judges, auditors, accountants and livestock judges, all make better judgements in their chosen areas than lay people (Shanteau 1988, 1992 and 1995).

However, making decisions that enhance welfare is not merely a case of the correct interpretation of facts. It also involves knowing the preference of the individual concerned. Experts and policy makers have no way of determining what an individual's true preferences are (Wright and Ginsburg 2012). They cannot determine how much of the revealed choice is rational or distorted, nor what level of intervention is necessary to accurately reveal true preferences.

This leads to what Rizzo and Whitman (2009a) call the 'knowledge problem' of new paternalism. Although the paternalist has better theoretical knowledge about cognitive and behavioural biases, they lack the knowledge of an individual's preferences, self-control problems and particular circumstances of time and place in which a decision is made. Without this information, the paternalist does not have the knowledge to provide practical intervention that enhances welfare.

To avoid the possibility of inappropriate intervention, Sunstein (2011) emphasises the need for careful analyses of rationale and its consequences. This suggests that the rigour of paternalist intervention is dependent on the level of knowledge and measurement methodology. With this in mind, the next section considers three cases that show the evolution of analysis over time. Then, we consider how the evolution of knowledge and measurement methodology may open up further areas of intervention. 


\section{Three cases of paternalistic intervention}

The following case studies show three different examples in which the evolution of knowledge has undermined the rationale of the intervention. The first example about chips explores a nudge-type intervention and its reliance on the state of scientific knowledge. The second case looks at smoking and has a broader view of costs. In societies where health costs are met by the taxpayer, paternalist arguments are tied to that of externalities as the costs are no longer borne just by the consumer. The final case looks at cycle helmets and relies on the knowledge associated with the effect of the intervention in achieving its goals and other consequences.

\section{Chips}

The Chip Group is a group partially funded by the New Zealand Government with the goal of reducing the fat (total and saturated) and salt content of deep-fried fish and chips (fries). Through advocacy, communication and training, the group seeks to set industry standards for such things as the size of the chips, the size of portions served and the fat and oil content. Their most prominent activity is a 'Best Chip Shop' competition in which shops undertake online training, write in explaining their healthy processes and send a sample of their chips to be analysed for fat content.

The chips are not tasted. In fact, taste is a notable omission from the judging criteria; a criterion that many, if not most, consumers would consider the most important when judging food. This raises concerns of manipulation by experts and the danger of distorting consumer preferences with incomplete information. However, the staff appear to have integrity and would not intentionally mislead people. They genuinely want to improve welfare, which illustrates that distortion can occur without intent. It may simply be a consequence of a strong focus on the goal of health.

The present author suggested to the group that to rename the competition 'the healthiest chip shop' would be more honest, but recent research now raises doubts over that definition. In particular, there is new evidence that saturated fats are not as bad for health as previously thought. For 40 years, consumers have been advised that they will live longer and have a better quality of life if they avoid fatty foods containing high cholesterol. In 1977 and 1983 respectively, the United States and United Kingdom governments produced guidelines that recommended reducing fat consumption to no more than 30 per cent of total energy intake and saturated fats to 10 per cent. However, it is now recognised that the guidelines were introduced without sufficient scientific evidence.

A large body of research now exists undermining the empirical support of the guidelines for both saturated fats and cholesterol. They include Petursson et al. (2012), who examined the health and lifestyle habits of more than 52,000 adults 
aged between 20 and 74 . They found that women with high cholesterol had lower risk of heart disease, cardiac arrest and strokes than women with low cholesterol. Similarly, Malhotra (2013) presented evidence that reducing saturated fat intake actually increased the risk of heart disease and obesity. He concluded it was time to 'bust the myth of the role of saturated fat in heart disease'.

Chowdhury et al. (2014) published a meta-analysis in the Annals of Internal Medicine, drawing on 27 randomised controlled trials and 49 observational studies involving more than 600,000 participants in 18 countries. They concluded that there was not 'clearly supportive evidence for current cardiovascular guidelines that encourage high consumption of polyunsaturated fats and low consumption of saturated fats'. While this study has been heavily criticised by many health professionals who have identified weaknesses in methodology, the debate reveals a more complex position. Cholesterol and saturated fat are essential for many body functions. They play an important role in building cell membranes, in mineral absorption, in interaction with proteins and in regulating pathways for cell signalling. If cholesterol levels are too low, it may actually increase the risk of cardiovascular disease.

In regards to cholesterol, the United States Government Dietary Guidelines Advisory Committee recently wrote a report that came to a similar conclusion, stating: 'Available evidence shows no appreciable relationship between consumption of dietary cholesterol and serum (blood) cholesterol. Cholesterol is not a nutrient of concern for overconsumption' (USDA 2015: 91). The government guidelines are set to change.

Many researchers are now stating that the health guidelines against fats should never have been issued, and lacked sufficient scientific evidence. Harcombe et al. (2015: 6) reviewed the control trials available at the time the guidelines were first issued and concluded:

It seems incomprehensible that dietary advice was introduced for 220 million Americans and 56 million UK citizens, given the contrary results from a small number of unhealthy men ... Dietary advice not merely needs review; it should not have been introduced.

A key lesson from the fat debate is the inertia and longevity of myths once they receive institutional support. For years, evidence was building but as late as 2010 the US Department of Agriculture repeated the call to keep saturated fat content below 10 per cent. By contrast, the most recent research suggests that healthy fats (saturated and unsaturated fats from whole food, animal and plant sources) should sit in a range from 50 to 85 per cent. The government guidelines may have actually reduced health and welfare. 


\section{Cigarette smoking}

Smoking was initially targeted by governments for paternalistic reasons, but in recent decades the rationale for intervention has included externalities and the cost to others. The problems of knowledge evolution are strongly illustrated here in what has been a battle of research. The purpose of this section is not to review all the literature on the costs of smoking, but to introduce the reader to the evolution of knowledge and how this produced a wide variation of results in those studies.

The justification for government intervention, that a third party is injured, has been applied to smoking, with a number of studies conducted to assess the true cost to society. In 1996, the cost of smoking to the United States, including externalities, was valued at US\$97 billion. This figure included US\$50 billion in direct health care costs, US\$7 billion in indirect morbidity costs including lost economic output when smokers can no longer work, and US $\$ 40$ billion from lost earnings once the smoker has died (see Pope 1999).

There is no doubt that smokers die early and are more likely to be absent from work with health problems. They cost more in health care when they are alive, perhaps up to 40 per cent more (Barendregt et al. 1997). A 1998 study strongly advocating legislation against tobacco usage noted that: 'The future medical costs of a young person taking up smoking today can be quite large-about $\$ 13,700$ in today's (1998) dollars over the course of a lifetime' (US Office of Public Affairs 1998). However, these early studies overlooked two very important points. First, the fact that smokers die earlier means they cost the country less in pensions. Second, because they die early, they incur fewer health costs in old age when health costs typically soar. The year before the Food and Drug Administration study, it was reported that 65-year-old Americans could expect to spend, on average, about US\$200,000 (in 1995 dollars) on health care before they die (Fuchs 2011: 164). A smoker who dies early saves the country a lot of money. In New Zealand, it has been shown that people over the age of 65 spend five times as much on health care than a person under 65 (Bryant et al. 2004). Consequently, a number of studies have been conducted showing that smokers actually save society money (Viscusi 1999; Barendregt et al. 1997).

These analyses show an evolution of knowledge and methodology with significant consequences for the justification for paternalistic intervention. More recently, Sloan (2004) added the costs associated with the effects of passive smoking on nonsmokers and the costs of fires started by cigarettes, and came to the conclusion that smoking does have a cost on the United States. He included medical expenses, productivity losses, effects of smoking on the health of others and non-medical expenditures. 
One of the problems with such an analysis is trying to identify the cost of a loss to life. The value of life has been a contentious area for economists. For example, one of the biggest problems relates to whether to value older people the same as younger people. Common sense would indicate that a younger person has more life ahead of them than an older person. However, when the Environmental Protection Agency tried to account for age differences in one assessment, it received large protests from senior citizens and had to abandon the discounting (Skrzycki 2003). Rightly or wrongly, this illustrates how the political process can infiltrate objective cost-benefit analysis.

As an approximation of life value, economists regularly use an estimate of future earnings that the smoker would have learned if s/he survived, but this raises new controversies. For example, it suggests that white men have a more valuable life because they typically earn more. By contrast, the unemployed, the retired and stayat-home mothers have no value. This raises the question as to whether we should give all people the same value as a working white man, or average it out. The first option would give a higher figure and suggests smoking imposes a high cost on society. The second option provides a lower figure and a lower cost to society. Sloan's analysis mentioned above used an average of US $\$ 100,000$ per year. This is a very high figure when compared to the average salary, and would raise the estimated cost of smoking. Notably, smokers are normally found in lower-paid jobs, which would imply a lower figure is more appropriate.

What this discussion reveals is the limitations of even the best economic evaluations. Barendregt et al. (1997: 1057) studied the effects of smoking in the Netherlands and concluded: 'Even a well-designed study of this type is marred by inevitable arbitrariness concerning what costs to include, which discount rate to apply, and what duration of follow-up to use'.

There are huge differences of opinion as to what to include. These differences can be the result of differences in judgement and the values of the analysts, but it can also be driven by motive, as lobbyists and experts become aware of these variations and exploit them for their own purposes. For example, in New Zealand an antismoking group commissioned an economist to determine the costs of smoking to New Zealand society, and although the reduced financial expenditure resulting from an early death on health expenditure and pensions was known, this figure was excluded from the report (Easton 1997).

With advances in knowledge, future studies may become more fine-tuned and accurate, in which case we may discover people's freedoms have been reduced erroneously. Of course, future findings may also show that governments could have been more severe. 


\section{Cycle helmets in New Zealand}

In 1986, Aaron Oaten was hit by a car while riding his bicycle to school. As a consequence, he spent eight months in a coma and when he awoke was paralysed and unable to speak (Duff 2010). A doctor advised his mother, Rebecca Oaten, that Aaron would 'almost certainly not have suffered brain damage' if he had been wearing a cycle helmet (Mullins 2000). His mother launched a campaign pressuring the government to introduce a law making it compulsory for all cyclists to wear helmets.

Rebecca Oaten's personal experience generated a great deal of sensitivity, and parliament on the day the bill was passed has been described as 'emotional', ${ }^{2}$ a reminder of Blumenthal's (2007) suggestion that law makers are also prone to emotional decision making. However, the legislation was not without empirical support. International evidence at the time supported the benefits of cycle helmets. For example, a 1987 study conducted in Seattle suggested that wearing cycle helmets could reduce head injury by 75 per cent and brain injury by 85 per cent (Thompson et al. 1989). Similarly, an Australian study released the year the law was introduced found that helmets reduced the risk of upper head injuries by 63 per cent and loss of consciousness by 86 per cent (Thomas et al. 1994).

The period following the law's enactment saw a reduction in cyclist head injuries. Povey et al. (1999) reported a 20 per cent reduction in head injuries for cyclists involved in crashes with motor vehicles, and a reduction of between 24 and 32 per cent for cyclists in non-motor vehicle crashes. They attributed this decline to the wearing of helmets. Similarly, Scuffham et al. (2000) found that cyclists of all age groups experienced a significantly reduced number of head injuries as a result of the wearing of helmets.

However, more recent research throws these conclusions into doubt. For example, Robinson (2001) noted that the reduced injury rate was part of a longer trend and, if the law was effective, a much larger improvement should have occurred in the year that helmets became compulsory. Similarly, Scuffham and Langley (1997: 8) found that the increase in helmet wearing 'had little association with serious head injuries to cyclists as a percentage of all serious injuries to cyclists'.

One of the notable trends since the law's introduction is a decrease in the number of cyclists. Clarke (2012) found cycling had declined by 51 per cent. This suggests that the reduction in injuries was not due to cycle helmets, but merely reflected the decline in the numbers of people cycling. Clark went further and argued that the new law forcing people to wear helmets had put many people off cycling. With the resultant loss of exercise and health, Clarke argues that the law actually contributed

2 L. Dalziel, personal communication, 1994. 
to 53 premature deaths per year. To put that figure in perspective, 17 cyclists died in 1993 compared to only nine in 2011. If Clarke's figures are correct, the law has contributed to significantly more deaths than it saved.

The New Zealand experience is similar to that of Canada, where different provinces have different laws. Some have mandatory helmets, some not. A survey of Canadian studies showed that where helmets have been introduced, they have had minimal injury benefit, with significant reductions in the numbers of people cycling (Teschke et al. 2015). Of note is the experience of Alberta, where bike accident head injuries actually increased after helmets were made mandatory. A number of explanations have been put forward for this, including how data is coded. However, one explanation was that wearing a helmet increased risk-taking behaviour (Sands 2003). This is an example of the Peltzman effect, in which safety regulations may have unintended consequences that counteract the intention; that is, targeted people respond by engaging in riskier behaviour (Peltzman 1975).

A subsequent paper analysed the research methods used in each of the New Zealand studies (Wang et al. 2013) and exposed an important point that legislators need to consider: the refinement of research over time and the variability of research technique. For example, it found that the results would vary depending on what years researchers used for their comparison, and whether time trends were considered. The authors send a strong warning (Wang et al. 2013: 12) to legislators:

To non-specialists, they may not be aware of the statistical issues involved in reaching certain conclusions. In fact, many statistically flawed studies have been cited extensively in public debate over bicycle helmet laws ... These studies may have influenced how the media, public and policymakers perceive bicycle helmets and mandatory helmet laws.

Other problems include the use of international comparisons when differences in the local environment have not been distinguished, and a failure to consider consumer preferences and unintended consequences.

A final lesson of this study of cycle helmets was the fact that the law's enactment did not result in any abrupt changes in the percentage of head injuries with the introduction of the legislation. Despite that finding, and attempts by lobby groups to repeal the law, the law remains intact, an illustration that a law with, at best, inconclusive results can be hard to repeal.

\section{Expert bias, path dependency and the law}

The case studies provide interesting observations on official intervention. The fatty chips case study reveals that incomplete information may be provided that distort preferences, even though there may be no intent to do so. It may simply be that the 
experts are concentrating on their goals and are not required to think about other consequences. Communication was made with the Chip Group and, although it was not measured, the perception was that the staff would not consciously be manipulative. This suggests that either they (1) were concentrating entirely on their institutional goals or (2) had different preferences to many people who would include taste as a criterion when considering food.

It was noted above that experts make better judgements than lay people in their chosen areas. However, a body of research shows that experts can be highly inaccurate at predicting the goals and preferences of non-experts. For example, Teno et al. (1995) found health professionals overestimated how many patients would prefer cardiopulmonary resuscitation. A significant part of this failing is that physicians tend to overemphasise the value of health when considering what makes people better off.

It is possible that paternalists and experts suffer from a number of biases that the lay person does not; that is, where their motives are so powerful that they undermine objective judgement. These biases may be subconscious and the paternalist may not be conscious of their strength, or they may be conscious and the paternalist believes the end justifies the means. The first of these we will call 'specialisationbias' in which specialists overvalue the area of their expertise. This can be linked to a number of well-documented phenomena. The first is selection bias, in which the people who choose to be an expert in a particular area do so because they value it more highly than other people. It can also be linked to the psychological phenomenon of projection, in which people use their own personal characteristics as a guide to human nature, and thereby believe their preferences are indicative of those of other people.

It is also possible that experts may be prone to representative bias in that the information they are exposed to on a daily basis raises the valence of that information. Health professionals are regularly exposed to the weaknesses of a behaviour, as they have to repair them. This can distort their perception of the population as a whole.

The final bias could be called 'missionary' or 'conversion' bias and refers to a situation in which the paternalist is motivated by a desire to convert others to a life that his experience or knowledge is superior to the one the targets are currently living. Some of those experiences can be very powerful-for example, the death of a loved one-and the paternalist can become so enthusiastic about the moral and intellectual righteousness of their proposal that it directs their judgement. In some instances, they may believe their mission is so important that the ends are more important than the methodology used. Not only does the paternalist gain pleasure and motivation from seeing the target improve their life, but the broader acceptance of those values reinforces the righteousness of the paternalist's beliefs. 
The smoking case study cited showed significant evolution in knowledge, with lobby groups presenting variations on the variables that they chose to include in their model. Modelling is arguably the scientific tool with the greatest ability to accommodate bias as the modeller has the choice of which variables to include or omit, and how much weighting to give to those variables.

The cycle helmet case study revealed that policy makers can also make emotional decisions, especially when dealing with life-and-death issues (in this case, a mother who had lost her son). The emotional content ensured the law was passed despite the poor knowledge-research base on the subject.

A significant problem comes from the way that knowledge evolves. Scientific knowledge is not definitive, but is constantly advanced and modified. The science on fats and cholesterol has shown significant evolution, with a subsequent reversal of a strongly held position. In fact, the initial advice may have been harmful. This points up the need for laws to be regularly modified or to be introduced with extreme care if the law has negative impacts such as a loss of freedom and control.

Despite a need for flexibility, two of the case studies revealed the problems of institutional inertia. Even when sufficient data appeared to show that the findings are at best equivocal, the guidelines on fat and cholesterol stayed in place. This same problem occurred in the case of cycle helmets, where significant action is required to overturn the law but the political momentum does not exist to do so. The law remains intact despite the inconclusive nature of the evidence.

This draws attention to the legislative process. In The Legal Process, Hart and Sacks (1958) argued that legislation evolves out of the interaction of different branches of government who draw on their respective areas of expertise. This process ensures that all relevant information is collected and results in rational and informed outcomes. The courts play an important role in addressing uncertainty and application of that legislation. It was assumed that this process would generate good public policy because the legislature was fully informed. However, it was soon recognised that laws could be passed that favoured well-organised lobby groups and were not necessarily for the public good (Eskridge and Frickey 1986).

Laws and other interventions are frequently the consequence of political activity. Downs (1957) focused on the election, voters and politicians as the determinants of policy, with policy focusing on the median voter. However, Schattschneider (1935), under his famous maxim 'policy creates politics', argued that policies shape political forces, including the organisation of political forces, their strategies and functions. He noted that many people have no idea what is going on and this provides opportunities for lobby groups to exploit their blindspot (Schattschneider 1960). 
For Schattschneider, policy is not an arena where all alternatives are equally plausible, as earlier decisions confer advantages on some policies at the expense of others. This historical institutionalism was developed further by Paul Pierson (2004), who argued that historical processes become embodied in institutions. The consequence is a path dependency or trajectories in which timing and sequences matter. Once started, it can be difficult to reverse those trajectories.

Posner (2000) had earlier drawn upon the concept of path dependency, which means the starting point strongly determines the direction of future developments. Posner linked this to the cost of change. The procedures for amending an existing piece of legislation are the same as for enacting a new one. Costs of change include information costs, transition costs and decision costs. Information costs are those associated with obtaining information about the consequences of legal options, while decision costs are those incurred while reaching a decision. Costs are much lower in retaining entrenched provisions than altering them, with the consequence being that legislative inertia can freeze bad laws in place (Varol 2015). As long as a law is working well enough, legislators may feel there are other more pressing issues, even if a better alternative exists.

Latham (2009) provides examples to show that statute enactment can be highly path dependent. Latham studied legislation on stem cell research in a number of countries and concluded that policies are at least partly, and in many cases quite powerfully, explained by path-dependency' (Latham 2009: 805). The policies and institutional structures that already exist guide and even pre-determine the shape of new policies. For example, in the United Kingdom parliamentarians referred to a pre-existing law, the Fertilisation and Embryology Act 1990, which listed permissible reasons for conducting research. Reference to this law made it easier to get the new legislation passed.

Inertia can occur at a number of levels of the legislative process. To further explore the possibility of inertia and path dependency, consider Hall's (1993) orders of policy change. For Hall, policy change may involve change in the level of policy instruments and changes in the policy instruments actually used. The budget rules and standard operating procedures used by government agencies may in themselves be vulnerable to path dependency.

Hall also said consideration should be given to the paradigm driving policy. A policy paradigm 'is an interpretative framework that operates in the policy-making process' (Kay 2005: 564). The policy paradigm determines what is rational in policy. It determines what ideas, instruments and standards drive policy, and how that policy is interpreted. Such a framework can become path dependent, not prohibiting change but limiting it to a particular set of options (Kay 2005). Paradigms do not 
just influence policy makers. They also influence the scientists that provide the knowledge on which legislators rely. Paradigms influence the judgement of scientists and the value they place on any given finding.

Path dependency can also come from vested institutional interests and incentives. Consider the Behavioural Insights Group established in the United Kingdom to introduce 'nudge' policies. If the group decides that increased intervention should be avoided because it increases manipulation of consumers, they may be putting themselves out of a job. Van der Meulen (1998) argues that if a stable relationship exists between government and research agencies, this in itself can create inertia. Agencies have limited budgets and the costs of switching to new agencies with new perspectives can be a deterrent to switching.

Not everyone accepts the historical power on regulation. It has been argued that past-oriented modes of law making, in particular common law, are in retreat. They are being replaced by future-oriented methods of law making such as statutes and regulations. Statutes are not precedents of future statutes. There is also the possibility of modifying or repealing a statute. This is particularly relevant for paternalism, as such interventions often occur by regulation, law or guideline. New paternalism could be included in these categories.

One of the sources of law making that is future oriented is regulatory agencies. This is the method of law most readily linked to the new paternalism. Regulatory agencies benefit from specialised knowledge of their subject area and the more rapid development of policy. However, that speed can be a two-edged sword. Speed can be an asset when conditions are changing rapidly, but it can undermine the law's legitimacy, as law is shaped quickly by the opinions of men who hold high office. By contrast, if law evolves slowly over time, it has its own direction independent of the particular people who make it.

The trend to forward-oriented modes of law making and increased use of regulation might not comfort those in fear of Rizzo and Whitman's (2009b) slippery slope.

This does not necessarily mean that regulatory excess exists. As society becomes more complicated, we would expect an increase in regulation. Markets and society are continually evolving and this evolution constantly opens the possibility for new harmful activities and products to be made available. Indeed, the market is so broad that it is impossible for any individual to be knowledgeable on all possible traps. Companies, through their consumer-behaviour specialists, can exploit weaknesses in human cognition to achieve sales that might not necessarily be welfare maximising. Given these market realities, the paternalist government can intervene and reduce the harm using its greater informational scope. Hence, further analysis is needed before it can be determined if regulatory excess exists. 
Regulations can speed up the process of making law but, if inertia exists, it is questionable whether this speed is being applied to the modification and repealing of regulations. Herein lies a concern raised in the fat/cholesterol case study. The guidelines are reviewed every five years but, despite this cycle of revision, the guidelines were slow to change. Given guidelines are at the least intrusive end of intervention, in comparison with laws and regulations, we could have expected change to occur with relative ease. It seems that once a policy exists, the onus shifts from proving that the law is beneficial to proving that the policy is detrimental. This shifting onus means that laws and regulations with marginal or no benefit may exist despite removing freedoms.

This conservatism may be linked to goals and resources of political parties. Given that political parties have limited resources to create and communicate policy, we would expect parties to focus on those policies that reflect their underlying ideology and vote-catching ability. This suggests that policy issues that do not align with any of these issues will be harder to dislodge due to the lack of political will.

\section{Conclusion}

A key justification for intervention is that people make suboptimal decisions, which lead to the question as to whether we should expect optimisation of decision making. In justifying their intervention in people's diets, Thaler and Sunstein (2003: 1168) make it very clear that they believe decisions should be optimised:

Of course, rational people care about the taste of food, not simply about health, and we do not claim that everyone who is overweight is necessarily failing to act rationally. It is the strong claim that all or almost all Americans are choosing their diet optimally that we reject as untenable.

There is little disagreement that consumer decision making is suboptimal, but this paper suggests that government decision making is also suboptimal. An expert's treatment of facts can be horribly flawed. Like consumers, governments can only make decisions based on the information available to them at the time.

Sunstein (2011) stressed the need for solid empirical backing for regulatory intervention; however, this paper has revealed there are limits to empirically based research. Compared to the knowledge we will have tomorrow, our knowledge is incomplete; in which case, legislation and regulating could be defined as incomplete processes. This in itself is not an argument against regulation, as long as the welfare gains from regulating exceed those from not doing so. However, it does imply that the limitations of knowledge need to be recognised and a flexible approach to regulation used. However, this paper has raised concerns about flexibility, with the strong possibility that inertial processes may be at work. 
Sunstein (2011) acknowledges that analysis has limitations and supports Greenstone's (2009) suggestion of retrospective analysis and a culture of experimentation and evaluation. Greenstone suggested creating a regulatory review board with the power to repeal legislation. In the United States, the need for the review of regulation is mandated by Presidential Executive Order 13563 (Office of the Press Secretary 2011), but it is notable that it only applies to 'existing significant regulations'. This leaves the possibility that minor regulations and interventions will not be revised.

It is worth noting that the guidelines for fat and cholesterol were revised every five years but stayed in place even though the evidence of benefit was at best equivocal. Under a culture of reviewing regulation with institutional inertia, the onus of proof seems to shift from proving benefit to proving cost or at least no benefit. Similarly, the cycle helmet example showed it is hard to repeal a law even when its benefit is hard to determine. Institutional inertia and the difficulty of organisational change can act as barriers to repealing law. The cost of revisioning and experimenting places significant extra resource and time demands on regulatory bodies.

The barriers to deleting laws and other interventions is of particular concern if there is merit in Rizzo and Whitman's claim that the new paternalist framework facilitates the rapid development of further intervention. The consequence is an increased loss of freedom. There is no rule of thumb to indicate when intervention goes too far. One of the problems limiting the development of such a line is the problem of measurement. In the cycling case, a possible option is to consider death or injury rates per thousand people. However, the problem is that there is huge variation in the type of injuries and some injuries may require more intervention than others.

The problem of measurement is multifaceted. Consider, for example, the study of smoking costs conducted in New Zealand referred to earlier (Easton 1997). In that case, the economist assumed that smokers get very little benefit from smoking because they are addicted. However, recent research has revealed that smoking is indeed enjoyable and is linked to stimulation of reward centres in the brain (Mansvelder and McGehee 2000).

Problems of measurement are also linked to one of the key rationales for intervention, and that is life expectancy. Thaler and Sunstein (2009: 5) seek to 'influence people's behaviour in order to make their lives longer, healthier, and better' (emphasis added). Similarly, proponents of a fat tax in New Zealand stated that their goal was to reduce early deaths, but no indication was given of what constituted an early death (Mhurchu et al. 2015). It is assumed that it is a death below the average. As the average grows, justification exists to intervene for those who have lifestyles that do not meet that average. 
Other approaches are available. For example, in the years between 1500-1800 AD, the lifespan for Europeans hovered between 30 and 40 years (Finch 2010). Seen in this light, a smoker who lives to 65 does well. It may be possible to identify an acceptable life span. If a person dies 12 years earlier than on average, at the age of 68 , this might be good enough given the comparison to the natural death rate before the introduction of modern medicine. If smokers have a life expectancy above 65 , they might not optimise the possibilities of modern knowledge, but their life may be good enough. In which case, intervention would not be necessary.

The evidence in this paper would strengthen the call for temporary laws and other interventions. Ginsburg et al. (2014) advocated the use of regulations that have an expiry date. Under such a process, proponents of regulation bear the cost of gaining an extension. However, to be effective, the cost of extension must at least be equal to the cost of introducing a new alternative legislation.

A temporary law enables legislators to gain information on the consequences of the law before the law becomes permanent. It also enables more time for empirical research and, consequently, may reveal that reducing freedoms is unnecessary. However, this can impose costs on constituents if they have to endure costs each time the law is changed. More worrying is the possibility that legislators, knowing that the law is temporary, may take less care when writing the law. The ease of enactment may also lead to an increase in regulations.

Another option comes from Zamir and Medina (2010), who argue that policies could include deontological thresholds for values such as liberty. They argued that, given freedom has a value, a law must pass a threshold before freedoms are lost and that threshold could be quantified and included in cost-benefit analyses. In a similar manner, the cost of modifying or repealing could be quantified and included in any research on the introduction of a law.

If we accept that policy makers are also prone to decision-making errors, we could create a decision-making guide for policy makers based on Sunstein and Thaler's framework. This could include cooling-off periods in that decision makers have a five-year period to allow the evolution of knowledge and research methodologies. Government decision makers could themselves be made to adhere to default rules. Drawing on Haybron and Tiberius (2012), policies could be guided by the rule of respecting people's status as autonomous agents and that welfare must be determined according to the targeted beneficiaries' own standards. Cost-benefit analysis should include weightings for loss of autonomy and respect (Zamir and Medina 2010).

Default rules could also include rules beyond which intervention is not necessary and the risk is acceptable. This could include death and injury rates per thousand participants, beyond which intervention is best left to the individual. A second rule 
could be that a death rate incurred by participants of 65 years or older does not justify intervention. This age is the minimum considered satisfactory. Failure to optimise by itself is not an excuse for intervention.

Information provision may be one of the best methods to enhance decision making with enhanced roles for consumer and information bureaus. This option is highly compatible with the possibilities of the internet. To remove the possibility of manipulation, advice should not attempt to affect preferences, only the state of the current knowledge, leaving the individual free to make their own informed choices.

In summary, governments can only make decisions with the information they have and within the time constraints they face. Consequently, the introduction of a law is strongly influenced by the information and knowledge that exists at the time of its introduction. However, knowledge continues to evolve long after laws have been enacted. This suggests that law and policy needs to reflect the temporal nature of knowledge. In theory, this can be done with regular review or temporary laws. However, previous authors have recognised the role of inertia and path dependency in law formation. Once a law is introduced, it is hard to dislodge. The onus of proof shifts from proving the benefit of the law to proving the law is not beneficial.

This paper has revealed a number of limitations to government intervention. The limitations of knowledge include the nature of knowledge creation, presentation and the nature by which knowledge evolves. Knowledge is transient, yet it is on this basis that individuals experience loss of agency. As a consequence, society can be governed by rules and policies that do not enhance welfare and restrict or distort individual agency.

\section{References}

Barendregt, J., Bonneux, L. and Van der Maas, P. 1997. 'The Health Care Costs of Smoking'. New England Journal of Medicine 337: 1052-1057. doi. org/10.1056/NEJM199710093371506

Blumenthal, J. 2007. 'Emotional Paternalism'. Florida State University Law Review 35: $1-72$.

Blumenthal-Barby, J.S. 2013. 'Choice Architecture: A Mechanism for Improving Decisions while Preserving Liberty?'. In Paternalism: Theory and Practice, edited by C. Coons and M. Weber. Cambridge: Cambridge University Press. doi. org/10.1017/CBO9781139179003.010

Bryant, J., Teasdale, A., Tobias, M., Cheung, J. and McHugh, M. 2004. 'Population Ageing and Government Health Expenditures in New Zealand, 1951-2051'. New Zealand Treasury Working Paper 04/14. New Zealand Tresaury, Wellington. 
Cholbi, M. 2013. 'Kantian Paternalism and Suicide Intervention'. In Paternalism: Theory and Practice, edited by C. Coons and M. Weber. Cambridge: Cambridge University Press. doi.org/10.1017/CBO9781139179003.007

Chowdhury, R., Warnakula, S., Kunutsor, S., Crowe, F., Ward, H., Johnson, L., Franco, O., Butterworth, A., Forouhi, N. Thompson, S., Khaw, K., Mozaffarian, D., Danesh, J. and Di Angelantonio, E. 2014. 'Association of Dietary, Circulating, and Supplement Fatty Acids with Coronary Risk: A Systematic Review and Meta-analysis'. Annals of Internal Medicine 160: 398-406. doi.org/10.7326/ M13-1788

Clarke, C. 2012. 'Evaluation of New Zealand's Bicycle Helmet Law'. New Zealand Medical Journal 125: 60-69.

Coons, C. and Weber, M. 2013. 'Introduction: Paternalism-Issues and trends'. In Paternalism: Theory and Practice, edited by C. Coons and M. Weber. Cambridge: Cambridge University Press. doi.org/10.1017/CBO9781139179003.001

De Marneffe, P. 2013. 'Self-sovereignty and Paternalism'Paternalism: Theory and Practice, edited by C. Coons and M. Weber. Cambridge: Cambridge University Press.

Downs, A. 1957. An Economic Theory of Democracy. New York: Harper.

Duff, M. 2010. 'Aaron's Tragedy Spurred Helmet Lady's Crusade'. Manawatu Standard, 22 August. stuff.co.nz/national/4031829/Aarons-tragedy-spurredHelmet-Ladys-crusade

Dworkin, G. 1972. 'Paternalism'. The Monist 56: 64-84. doi.org/10.5840/ monist 197256119

Easton, B. 1997. 'The Social Costs of Tobacco and Alcohol Misuse'. Public Health Monograph Series No. 2. University of Wellington, Wellington School of Medicine, Wellington.

Eskridge Jr, W.N. and Frickey, P.P. 1986. 'Legislation Scholarship and Pedagogy in the Post-Legal Process Era'. University of Pittsburgh Law Review 48: 691-731.

Finch, C. 2010. 'Evolution of the Human Lifespan and Diseases of Aging: Roles of Infection, Iinflammation, and Nutrition'. In Proceedings of the National Academy of Sciences of the United States of America 107 (1): 1718-1724. doi.org/10.1073/ pnas.0909606106

Fuchs, V. 2011. Who Shall Live? Health, Economics and Social Choice. 2nd ed. Hackensack: World Scientific Publishing. doi.org/10.1142/8167 
Gill, N. and Gill, M. 2012. 'The Limits to Libertarian Paternalism: Two New Critiques and Seven Best-practice Imperatives'. Environment and Planning C: Politics and Space 30: 924-940. doi.org/10.1068/c11149r

Ginsburg, T., Masur, J. and McAdams, R. 2014. 'Libertarian Paternalism, Path Dependence, and Temporary Law'. University of Chicago Law Review 81: 291359.

Glaeser, E. 2005. 'Paternalism and Psychology'. NBER Working Paper No. w11789. National Bureau of Economic Research, Cambridge.

Greenstone, M. 2009. 'Toward a Culture of Persistent Regulatory Experimentation and Evaluation'. In New Perspectives on Regulation, edited by D. Moss and J. Cisternino. Cambridge UK: The Tobin Project.

Hall, P. 1993. 'Policy Paradigms, Social Learning, and the State: The Case of Economic Policymaking in Britain'. Comparative Politics 25: 275-96. doi. org/10.2307/422246

Harcombe, Z., Baker, J., Cooper, S., Davies, B., Sculthorpe, N., Di Nicolantonio, J. and Grace, F. 2015. 'Evidence from Randomised Controlled Trials Did Not Support the Introduction of Dietary Fat Guidelines in 1977 and 1983: A Systematic Review and Meta-analysis'.Open Heart 2 (1): e000196. doi. org/10.1136/openhrt-2014-000196

Hart, H.M. and Sacks, A.M. 1958. The Legal Process: Basic Problems in the Making and Application of Law, Cambridge: Harvard University Press.

Haybron, D. and Tiberius, V. 2012. 'Normative Foundations for Well-being Policy'. Papers on Economics and Evolution No. 1202. Germany: Max Planck Institute of Economics, Evolutionary Economics Group.

Husak, D. 2013. 'Penal Paternalism'. In Paternalism: Theory and Practice, edited by C. Coons and M. Weber. Cambridge: Cambridge University Press. doi. org/10.1017/CBO9781139179003.003

Kay, A. 2005. 'A Critique of the Use of Path Dependency in Policy Studies'. Public Administration 83: 553-564. doi.org/10.1111/j.0033-3298.2005.00462.x

Latham, S. 2009. 'Between Public Opinion and Public Policy: Human Embryonic Stem-Cell Research and Path-Dependency'. Journal of Law, Medicine \& Ethics 37: 800-806. doi.org/10.1111/j.1748-720X.2009.00451.x

Leoni, B. 1991. Freedom and the Law. 3rd ed. Indianapolis: Liberty Fund. 
Loewenstein, G. and O'Donoghue, T. 2006. 'We Can Do This the Easy Way or the Hard Way: Negative Emotions, Self-Regulation, and the Law'. University of Chicago Law Review 73: 183-206.

Malhotra, A. 2013. 'Saturated Fat Is Not the Major Issue'. British Medical Journal 347: f6347. doi.org/10.1136/bmj.f6340

Mansvelder, H.D. and McGehee, D.S. 2000. 'Long-term Potentiation of Excitatory Inputs to Brain Reward Areas by Nicotine'. Neuron 27: 349-357. doi. org/10.1016/S0896-6273(00)00042-8

Mhurchu, C., Eyles, H., Genc, M., Scarborough, P., Rayner, M., Mizdrak, A., Nnoaham, K. and Blakely, T. 2015. 'Effects of Health-related Food Raxes and Subsidies on Mortality from Diet-related Disease in New Zealand: An Econometric-epidemiologic Modelling Study'. PloS ONE 10: 1-17. doi. org/10.1371/journal.pone.0128477

Mullins, J. 2000. 'Hard-Headed Choice'. New Scientist, 22 July, 16-17.

Muramatsu, R. and Fonseca, P. 2009. 'Freedom of Choice in a World of Boundedly Rational Agents: Remarks About the Light Paternalistic Policy Implications of Behavioral Economics'. IAREP Papers and Proceedings. International Association for Research in Economic Psychology.

Office of the Press Secretary 2011. 'Executive Order 13563-Improving Regulation and Regulatory Review'. Federal Register 76 (14): 3821-3823. www.gpo.gov/ fdsys/pkg/FR-2011-01-21/pdf/2011-1385.pdf

Peltzman, S. 1975. 'The Effects of Automobile Safety Regulation'. Journal of Political Economy 83: 677-726. doi.org/10.1086/260352

Petursson, H., Sigurdsson, J., Bengtsson, C., Nilsen, T. and Getz, L. 2012. 'Is the Use of Cholesterol in Mortality Risk Algorithms in Clinical Guidelines Valid? Ten Years Prospective Data from the Norwegian Hunt 2 Study'. Journal of Evaluative Clinical Practice 18: 159-168. doi.org/10.1111/j.1365-2753.2011.01767.x

Pierson, P. 2004. Politics in Time: History, Institutions, and Social Analysis. Princeton: Princeton University Press. doi.org/10.1515/9781400841080

Pope, T.M. 1999. 'Balancing Public Health Against Individual Liberty: the Ethics of Smoking Regulations'. University of Pittsburgh Law Review 61: 419-498.

Posner, R. 2000. 'Past-Dependency, Pragmatism, and Critique of History in Adjudication and Legal Scholarship'. University of Chicago Law Review 67: 573-606. doi.org/10.2307/1600335 
Povey, L., Frith, W. and Graham, P. 1999. 'Cycle Helmet Effectiveness in New Zealand'. Accident Analysis \& Prevention 31: 763-770. doi.org/10.1016/ S0001-4575(99)00033-0

Rizzo, M. and Whitman, D. 2009a. "The Knowledge Problem of the New Paternalism'. Bringham Young University Law Review 4: 905-968.

_ 2009b. 'Little Brother is Watching You: New Paternalism on the Slippery Slopes'. Arizona Law Review 51: 685-739.

Robinson, D. 2001. 'Changes in Head Injury with the New Zealand Bicycle Helmet Law'. Accident Analysis \& Prevention 33: 687-691. doi.org/10.1016/ S0001-4575(00)00073-7

Sands, D. 2003. 'Head Injuries Up After Helmet Law'. Edmonton Sun, July 12.

Scoccia, D. 2013. 'The Right to Autonomy and the Justification of Hard Paternalism'. In Paternalism: Theory and Practice, edited by C. Coons and M. Weber. Cambridge: Cambridge University Press. doi.org/10.1017/CBO9781139179003.005

Scuffham, P., Alsop, J., Cryer, C. and Langley, J. 2000. 'Head Injuries to Bicyclists and the New Zealand Bicycle Helmet Law'. Accident Analysis \& Prevention 32: 565-573. doi.org/10.1016/S0001-4575(99)00081-0

Scuffham, P. and Langley, J. 1997. 'Trends in Cycle Injury in New Zealand Under Voluntary Helmet Use'. Accident Analysis \& Prevention 29: 1-9. doi.org/10.1016/ S0001-4575(96)00054-1

Shanteau, J. 1988. 'Psychological Characteristics and Strategies of Expert Decision Makers'. Acta Psychologica 68: 203-215. doi.org/10.1016/00016918(88)90056-X

1992. 'Competence in Experts: the Role of Task Characteristics'. Organizational Behavior and Human Decision Processes 53: 252-266. doi.org/10.1016/07495978(92)90064-E 1995. 'Expert Judgment and Financial Decision Making'. Risky Business 1632.

Schattschneider, E.E. 1935. Politics, Pressures and the Tariff: A Study of Free Private Enterprise in Pressure Politics, as Shown in the 1929-1930 Revision of the Tariff. New York: Prentice Hill. 1960. The Semi-Sovereign People: A Realist's View of Democracy in America. New York: Holt, Reinhart and Winston. 
Skrzycki, C. 2003. 'Under Fire, EPA Drops the "Senior Death Discount". Washington Post, 13 May.

Sloan, F. 2004. The Price of Smoking. Cambridge MA: MIT Press.

Sunstein, C.R. 2011. 'Empirically Informed Regulation'. University of Chicago Law Review 78: 1349-1429.

Teno, J., Hakim, R., Knaus, W., Wenger, N., Phillips, R., Wu, A., Laid, P., Connors, A., Dawson, N. and Lynn, J. 1995. 'Preferences for Cardiopulmonary Resuscitation'. Journal of General Internal Medicine 10: 179-186. doi. org/10.1007/BF02600252

Teschke, K., Koehoorn, M., Shen, H. and Dennis, J. 2015. 'Bicycling Injury Hospitalisation Rates in Canadian Jurisdictions: Analyses Examining Associations with Helmet Legislation and Mode Share'. BMJ open 5 (11): p.e008052. doi. org/10.1136/bmjopen-2015-008052

Thaler, R. and Sunstein, C. 2003. 'Libertarian Paternalism Is Not an Oxymoron'. University Chicago Law Review 70 (4): 1159-1168. doi.org/10.2307/1600573

— 2009. Nudge: Improving Decisions About Health, Wealth, and Happiness. New Haven: Yale University Press.

Thomas, S., Acton, C. and Nixon, J. 1994. 'Effectiveness of Bicycle Helmets in Preventing Head Injury in Children: Case-Control Study'. British Medical Journal 308: 173-176. doi.org/10.1136/bmj.308.6922.173

Thompson, R., Rivara, F. and Thompson, D. 1989. 'A Case-Control Study of the Effectiveness of Bicycle Safety Helmets'. New England Journal of Medicine 320: 1360-1367. doi.org/10.1056/NEJM198905253202101

USDA 2015. Scientific Report of the 2015 Dietary Guidelines Advisory Committee. United States Department of Agriculture.

US Office of Public Affairs 1998. The Economic Costs of Smoking in the United States and the Benefits of Comprehensive Tobacco Legislation. www.treasury.gov/presscenter/press-releases/Documents/tobacco.pdf

Van der Meulen, B. 1998. 'Science Policies as Principal-Agent Games: Institutionalization and Path Dependency in the Relation Between Government and Science'. Research Policy 27: 397-414. doi.org/10.1016/S00487333(98)00049-3

Varol, O. 2015. 'Constitutional Stickiness'. UC Davis Law Review 49: 899. 
Viscusi, K. 1999. 'The Government Composition of the Insurance Costs of Smoking'. Journal of Law and Economics 42: 575-610. doi.org/10.1086/467435

Wang, J., Grzebieta, R., Walter, S. and Olivier, J. 2013. 'An Evaluation of the Methods Used to Assess the Effectiveness of Mandatory Bicycle Helmet Legislation in New Zealand'. Paper presented at Australasian College of Road Safety Conference, Adelaide, South Australia.

Wellman, C. 2005. 'Samaritanism and the Duty to Obey the Law'. In Is there a duty to obey the law?, edited by in C. Wellman and J. Simmons. Cambridge: Cambridge University Press. doi.org/10.1017/CBO9780511809286.008

Wright, J. and Ginsburg, D. 2012. 'Behavioural Law and Economics: Its Origins, Fatal Flaws, and Implications for Liberty'. North Western University Law Review 106: 1033-90.

Zamir, E. and Medina, B. 2010. Law Economics and Morality. New York: Oxford University Press. doi.org/10.1093/acprof:oso/9780195372168.001.0001 
This text is taken from Agenda, Volume 24-Number 1, 2017, edited by William Coleman, published 2017 by ANU Press, The Australian National University, Canberra, Australia.

dx.doi.org/10.22459/AG.24.01.2017.04 